\title{
Titanium Dioxide Nano-Particles Recovered From Red Sediment Placer Low Graded IImenite With Microwave Heating Followed by Sds Solution
}

SATYA SRIKANT ( $\square$ satya.srikant@gmail.com )

SRM Institute of Science and Technology https://orcid.org/0000-0001-7490-043X

Raghupatruni Rao

CSIR-Institute of Minerals and Materials Technology (IMMT)

\section{Article}

Keywords: Microwave energy, reductant, susceptor, ilmenite, titania slag

Posted Date: January 20th, 2022

DOI: https://doi.org/10.21203/rs.3.rs-1273520/v1

License: (c) (1) This work is licensed under a Creative Commons Attribution 4.0 International License.

Read Full License 


\section{Abstract}

Microwave is source of environmentally heating of minerals. The present paper deals about the recovery of titania in form of slag with microwave reduction of oxidized ilmenite. This paper was further investigated for the recovery of upgraded titania from microwave heat treatment of titania obtained from ilmenite. The results show upgraded titania contain a very high graded $\mathrm{TiO}_{2}$ components with less amounts of alkaline-earth materials and other impurities as compared to titanium obtained from ilmenite. The upgraded titania was produced the crack and development of pores in the sample surface. An attempt was also made to prepare nano-titania material with suitable leaching and microwave heating. The results with TEM analysis and XRD analysis show the formation of nano titanium dioxide particles. The titanium dioxide nano materials can widely be used in pharmacy and medical industries, paints and coatings industries,, catalysts, semiconductors, optoelectronics industries and others including water filters areas.

\section{Introduction}

Microwaves are the most innovative heating source used in metal extraction. It depends upon the properties of the material with interactions of electromagnetic fields present in microwave irradiation. When the microwaves are applied to atoms and molecule of dielectric materials (such as ilmenite), then the dipoles align and flip around since the applied electromagnetic field is alternating [1-5]. As a result, the material got heat up when stored internal energy is lost to friction. The reducing agent like carbon particles act as a susceptors in microwave furnace which further enhance the heat [3-5].

Titanium is the 9th most abundant element in the earth's crust. There are many applications of Titanium and its products titanium dioxide $\left(\mathrm{TiO}_{2}\right)$ in industrial and commercial markets specifically in the areas of paints, coatings, pharmacy, medical, papers, semiconductors, inks, optoelectronics, etc. Titanium dioxide $\left(\mathrm{TiO}_{2}\right)$ is commonly found in nature in the form of "ilmenite" ores containing $\mathrm{TiO}_{2}$ associated with various oxide impurities. Usually, Ilmenite ores are upgraded into "synthetic rutile" products containing 92-95 wt. $\% \mathrm{TiO}_{2}$ with leaching of ilmenite ores with mineral acids [6-7].

The present study mainly concentrates for the preparation of a titanium dioxide $\left(\mathrm{TiO}_{2}\right)$ in form of slag and an attempt to produce the nano- titanium dioxide minerals. Since the era of nanotechnology, titanium dioxide nano-materials have now became the topic of core research, owing to their huge cost and complex production process. These nano- titanium dioxide particles are widely used in the applications of medicine and pharmacy technology, degradation of toxins, paints and coating technology, manufacturing of mirrors or fog-free windows, food hygiene, inactivation of microorganisms, semiconductors and optoelectronics technologies, removing pollutants from buildings and environmental protection or building industry.

The microwave furnace is used for heating the sample for entire investigations and has a great significance as it is a eco friendly process [8-9]. 


\section{Materials And Methods}

Initially, the ilmenite sample with low grade was recovered from red sediment badland topography of South East coast of India; obtained from method of bromoform sinks followed by magnetic separation using permanent magnetic separator [10-11]. Further low grade ilmenite sample was subjected to have roasting process; followed with leaching, which is an effective process for preparation of synthetic rutile. This sample was processed with wet chemical method which produced orange red colour after dissolution in solution of sulphuric acid and ammonium sulphate. Ilmenite was first crushed and ground into different sizes and then it was subjected to above mentioned leaching process. Further pre oxidized low graded ilmenite mineral was heated in microwave furnace in presence of Argon inert gas at $1.5 \mathrm{KW}$ to reach at least $900^{\circ} \mathrm{C}$ for thirty five minutes which produced the sample in form of titania slag and iron metal [12-13]. The titania slag was again microwave heated in absence of Argon inert gas. This extra microwave heating was performed because a major portion of iron oxide samples were converted in ferric state and the reduced titanium oxides were converted in tetravalent state, so that a substantial portion of the glassy silicate phase was decomposed. The schematic sketch for low grade ilmenite sample in the microwave furnace for heat treatment is shown in Figure 1. The microwave furnace used for the present investigation was $\mathrm{G} \mathrm{N}$ Tech, $2.45 \mathrm{GHz}, 6 \mathrm{KW}$. PANalytical X-Pert automated X-ray powder diffractometer with Cu-Ka radiation $\left(\lambda=1.54 \hat{A}\right.$ ) and scanning angle ranging from $5^{\circ}$ to $70^{\circ}$ (scanning rate of $0.05^{\circ} / \mathrm{sec}$ ) was used for phase analysis of heated pre-oxidized ilmenite sample. Morphological features of heated ilmenite sample were then observed with a field effect scanning electron microscope (FESEM). The FESEM model used for present investigation is Supra 55; Zeiss, (made in Germany), which is available in CSIR-IMMT, Bhubaneswar.

An attempt has also been made to prepare nano-materials from ilmenite concentrate in the present investigations. Low grade Ilmenite was ground to fine powder with $<50$ micron $(\mu \mathrm{m})$ size particle and was dissolved with concentrated sulphuric acid. As an agitated reactor, the concentrated sulphuric acid was heated around $100-120^{\circ} \mathrm{C}$ in microwave oven in presence of Argon inert gas [12-13]. The powder ilmenite was mixed slowly. It has been observed that the temperature of the mixture was firstly increased slowly to $150^{\circ} \mathrm{C}$ and then suddenly increased to $230^{\circ} \mathrm{C}$. The temperature of the mixture was controlled by purging air and pouring of dilute sulphuric acid. Dissolution of the dissolved mass was carried out in dilute acid and un-reacted mass was filtered out with the help of settling process. The composition of the dissolution liquor was performed with standard wet method. Synthesis of nano-titanium dioxide has been carried out with sodium dodecyl sulphate (SDS) solution at low temperature. The experimental plan for preparation of nano Titania $\left(\mathrm{TiO}_{2}\right)$ material is shown in Fig. 2 with flow sheet.

\section{Results And Discussion}

\subsection{Changes in Mineral Phase}

The Titania slag as shown in Fig. 3 mainly shows a typical XRD pattern It showed several major pseudobrookite peaks $(P)$ and many minor Iron (I) peaks were observed in entire $2 \bigotimes$ region for Cu-Ka 
radiation from $5^{\circ}$ to $70^{\circ}$ scanning angle. It consists of $\mathrm{W}_{3} \mathrm{O}_{5}$ phase, with $\mathrm{W}$ denoting the phase cations. This phase got change, during microwave heating of titania slag upto $900 \otimes \mathrm{C}$ for 40 minutes. Figure 4 shows a typical XRD pattern after titania slag was again subjected to the microwave heating. It showed the major rutile peak $(R)$, pseudobrookite peak $(P)$ and titanium dioxide peak and minor ilmenite $(X)$ peaks for given Cu-Ka radiation. It was also observed that the $\mathrm{Ti}^{+3}$ constituents in form of rutile $\left(\mathrm{TiO}_{2}\right)$ was freed in pseudobrookite phase during the reduction process. Decrepitation of titania slag occur during oxidation of $\mathrm{W}_{3} \mathrm{O}_{5}$ phase which causes cracking in slag, as it is clearly seen FESEM figures.

\subsection{Morphological Analysis}

The FESEM of oxidized ilmenite is shown in Fig. 5. The Titania slag under FESEM as shown in Fig. 6, which clearly observes the presence of metallic iron in form of dots and with $\mathrm{W}_{3} \mathrm{O}_{5}$ (in a matrix). Also the slag shows iron metals with small irregular dots / prills nuggets. At higher temperature when titania slag again heated, the micro cracks appear as shown in Fig. 7 in the slag sample. During this state, it was observed to have radical changes in the crystal slag structure. The mineral phase studies and morphological studies indicated that the iron ( $\mathrm{Fe}$ ) concentration level in the heat treated titania slag was significantly found lower than the slag obtained without heat treatment. It also improved the quality of synthetic rutile after heat treatment.

\subsection{Titanium dioxide slag Chemical Analysis}

Chemical analysis of untreated titanium dioxide (titania) slag and heat treated titania slag were carried out to understand the difference between them. It was observed that the Titanium weight \% increases gradually from untreated slag to heat treated slag and also decrease in iron contents. The chemical analysis results of samples are shown in Tables 1 and 2

Table 1 Chemical analysis of untreated titanium dioxide (titania) slag

\begin{tabular}{|llllllll|}
\hline $\mathrm{TiO}_{2} \%$ & $\mathrm{Fe}(\mathrm{M}) \%$ & $\mathrm{FeO} \%$ & $\mathrm{SiO}_{2} \%$ & $\mathrm{MnO} \%$ & $\mathrm{MgO} \%$ & $\mathrm{CaO} \%$ & $\mathrm{Cr}_{2} \mathrm{O}_{3} \%$ \\
\hline 83.6 & 2.1 & 12.2 & 0.18 & 0.80 & 0.93 & 0.16 & 0.03 \\
\hline
\end{tabular}

Table 2 Chemical composition of microwave heated titanium dioxide (titania) slag 


\begin{tabular}{|lllllll|}
\hline $\mathrm{TiO}_{2} \%$ & Total Fe content \% & $\mathrm{MnO} \%$ & $\mathrm{MgO} \%$ & $\mathrm{CaO} \%$ & $\mathrm{Cr}_{2} \mathrm{O}_{3} \%$ & LOI \% \\
\hline 92.7 & 3.9 & 0.63 & 0.64 & 0.11 & 0.02 & 2 \\
\hline
\end{tabular}

\subsection{Formation of Nano-Titania particles}

As already shown in Fig. 2 in materials and method section, about the experimental procedure to prepare nano titanium dioxide materials from red sediment placer ilmenite. The dissolution liquor composition obtained from $250 \mathrm{~kg}$ batch within two stages of leaching from red sediment low grade ilmenite is shown in Table 3i.e Leached and calcined synthetic titanium dioxide product was prepared from low grade ilmenite by generating soda ash roasted titanium dioxide slag followed by slag leaching by $6 \mathrm{M} \mathrm{HCl}$ (shown in Fig. 8). The dissolution liquor contains 95.4 gram per litre (gpl) hydrated titania $\left(\mathrm{TiO}_{2}\right)$. Thermogravimetry Thermal Differential Analysis (TG/DTA), X-Ray Diffraction (XRD) analysis and Transmission electron microscopy (TEM) analysis were performed to characterize the hydrated titanium dioxide as shown in Table 4. Form the results of TG-DTA analysis, hydrated titanium dioxide (titania) were seen at $450^{\circ} \mathrm{C}$. XRD analysis of hydrated titania for both dried and calcined at $450^{\circ} \mathrm{C}$ was observed in anatase phase.

Table 3: Dissolution liquor composition

\begin{tabular}{|lll|}
\hline Sample & $\begin{array}{l}\text { Crystallite size }(X) \\
\text { (With XRD analysis) }\end{array}$ & $\begin{array}{l}\text { Particle size }(Y) \\
\text { (With TEM analysis) }\end{array}$ \\
\hline Dried at $120^{\circ} \mathrm{C}$ & $4.1 \mathrm{~nm}$ & $20 \mathrm{~nm}$ \\
\hline Calcined at $450^{\circ} \mathrm{C}$ & $31.3 \mathrm{~nm}$ & 20 to $50 \mathrm{~nm}$ \\
\hline
\end{tabular}

Table 4: Thermal Analysis (TG/DTA) for crystallite size XRD data and particle size with TEM analysis

\begin{tabular}{|c|c|c|c|c|c|}
\hline $\begin{array}{l}\mathrm{TiO}_{2} \\
(\mathrm{~g} / \mathrm{I})\end{array}$ & $\begin{array}{l}\text { Total Fe } \\
(\mathrm{g} / \mathrm{I})\end{array}$ & $\begin{array}{l}\mathrm{FeSO}_{4} \\
(\mathrm{~g} / \mathrm{I})\end{array}$ & $\begin{array}{l}\mathrm{Fe}_{2}\left(\mathrm{SO}_{4}\right)_{3} \\
(\mathrm{~g} / \mathrm{I})\end{array}$ & $\begin{array}{l}\text { Solid content (Kg) } \\
\text { Un-reacted IImenite }\end{array}$ & $\begin{array}{l}\text { Weight of } \\
\mathrm{TiO}_{2}(\mathrm{Kg})\end{array}$ \\
\hline 95.4 & 44 & 109.4 & 48.2 & 22 & 5 \\
\hline
\end{tabular}


The dissolution liquid of hydrated titania sample was further dissolved with Sodium Dodecyl Sulphate (SDS) solution for observing the synthesis of nano-titanium dioxide. The XRD analysis for nano titanium dioxide particles at different calcined conditions are shown in Fig. 9 where as transmission electron micrograph of nano-titania particles are shown in Fig. 10 with $20 \mathrm{~nm}$ and $50 \mathrm{~nm}$ high resolution. Table 5 shows the crystalline size of nano-titania minerals in nanometre with TEM analysis after addition of SDS solution to hydrated titania solution. It clearly seen from Table 5 , the crystalline size were $6.0 \mathrm{~nm}$ after drying at $120^{\circ} \mathrm{C}, 10.2 \mathrm{~nm}$ after calcined at $450^{\circ} \mathrm{C}, 15.9 \mathrm{~nm}$ after calcined at $550^{\circ} \mathrm{C}$ and $18.7 \mathrm{~nm}$ after calcined at $750^{\circ} \mathrm{C}$.

Table 5: TEM analysis after adding SDS solution to hydrated titania solution

\begin{tabular}{|lllll|}
\hline Sample $(\mathrm{nm})$ & Dried at $\mathbf{1 2 0 ^ { \circ } \mathrm { C }}$ & Calcined at $\mathbf{4 5 0 ^ { \circ } \mathrm { C }}$ & Calcined at $\mathbf{5 5 0 ^ { \circ } \mathrm { C }}$ & Calcined at $\mathbf{7 5 0 ^ { \circ } \mathrm { C }}$ \\
\hline Crystalline size & $6.0 \mathrm{~nm}$ & $10.2 \mathrm{~nm}$ & $15.9 \mathrm{~nm}$ & $18.7 \mathrm{~nm}$ \\
\hline
\end{tabular}

These titanium dioxide nano-particles are widely used in the applications of medicine and pharmacy technology, degradation of toxins, paints and coating technology, manufacturing of mirrors or fog-free windows, food hygiene, inactivation of microorganisms, semiconductors and optoelectronics technologies, removing pollutants from buildings and environmental protection or building industry.

\section{Conclusions}

Heavy placer minerals with huge amount are found in Indian coast. Many Government of India organizations and Research Universities such as CSIR - IMMT, Indian Rare Earths Limited as well as SRM Institute of Science and Technology, several IITs and many private companies are recovering individual minerals. This paper deals with mines to nano materials from Red Sediments badlands topography minerals. Following are the outcomes and findings for this innovative work:

- The samples of red sediments badlands was collected from the South East Coast of India in which Low grade Ilmenite sample was recovered from the bromoform sinks followed by magnetic separation.

- Pre-oxidized low grade ilmenite was subjected to microwave heating in presence of Inert gas which produced the titanium dioxide in form of slag.

- This titania slag was again microwave heated in absence of inert gas, as small the iron contents were transformed to ferric state and reduced titanium oxides were transformed to tetravalent state. It has also been observed that major glassy phase portion was discomposed. 
- Titania rich slag can be obtained upto $92.7 \%$ by upgrading and heating the titania slag in microwave furnace with less metallization .

- An attempt was made to prepare nano-titania partcles from low grade ilmenite minerals. Leached and calcined synthetic titanium dioxide product was prepared from low grade ilmenite by generating roasted soda ash slag sample followed by slag leaching with hydrochloric acid. It produced dissolution liquor in form of hydrated titania.

- Hydrated titania sample was dissolved with Sodium Dodecyl Sulphate (SDS) solution for producing the nano-titanium dioxide. The results with XRD analysis, TEM analysis at various calcined conditions confirm about nano-titania $\left(\mathrm{TiO}_{2}\right)$ minerals. These titanium dioxide nanoparticles are widely used in various applications in pharmacy and medical industries, semiconductors and optoelectronics technologies, paints and coating technology, manufacturing of mirrors or fog-free windows, food hygiene, inactivation of microorganisms, removing pollutants from buildings and environmental protection.

- Thus one can say that present investigations is very effective in producing the titanium nanoparticles from heavy placer ilmenite. Further studies are still in progress.

\section{Declarations}

\section{ACKNOWLEDGEMENTS}

The authors are thankful to CSIR-Institute of Minerals and Materials Technology, Bhubaneswar to carry out the research work.

\section{References}

1. Chen TT, Dutrizac JE, Haque KE, Wyslouzil W and Kashyap S., "The Relative Transparency of Minerals to Microwave Radiation" Canadian metallurgical quarterly, 1984, Vol 23(1), pp 349-351.

2. Bhima Rao R and Patnaik N., "Microwave Energy in Mineral Processing - a Review" IE(I) Mineral Journal, 2004, Vol 84(1), pp 56-61.

3. Pickles C A., "Microwaves in extractive metallurgy: Part 1 - A Review of Fundamental” Mineral Engineering, Elsevier Journal, 2009, Vol 1, pp 1102-1111, doi:10.1016/j.mineng.2009.02.015.

4. Pickles C A., "Microwaves in extractive metallurgy: Part 2 - A Review of Applications. " Mineral Engineering, Elsevier Journal, 2009, Vol 1, pp 1112-1118 doi:10.1016/j.mineng.2009.02.014.

5. Kelly R.M, Rowson N.A, "Microwave Reduction of oxidised ilemenite concentrates" Minerals Engineering, Vol.11, No. 11, 1998, pp. 1427-1438

\section{Borowiec $\mathrm{K}$, Grau A E, Gueguin $\mathrm{M}$, and Turgeon J F, "Method to upgrade titania slag and resulting products", US Patent number 5,830,420, Nov.3, 1998.}

7. Van Dyk, Vegter N M, Visser C P, T de Lange, Winter J D, Walpole E A and Nell J, "Beneficiation titania slag by oxidation and reduction treatment”, US Patent number 6,830,024 B1, Oct.12, 2004. 
8. Satya Sai Srikant, "Microwave Processing in Beach Placer Heavy Minerals" PhD Thesis, SOA University, India, 2014.

9. S. Samal, B.K. Mohapatra, P.S. Mukherjee and S.K. Chatterjee, "Integrated XRD,EPMA and XRF study of ilmenite and titania slag used in pigment production" Journal of alloys and compounds, Vol 474, 2009, pp- 484-489.

10. Babu, N., Vasumathi, N., Rao, R B., Recovery of Ilmenite and Other Heavy Minerals from Teri Sands (Red Sands) of Tamil Nadu, India. Journal of Minerals and Materials Characteristics and Engg, 2009, 8, 149-159.

11. Laxmi, T., Rao, R B., Badland topography of coastal belt red sediment deposits of India: A potential resource for industrial minerals. Mines and Minerals Reporter, 2010, 3, 12-18

12. Satya Sai Srikant, P S Mukherjee, and R. Bhima Rao, "Applications of microwave oven and microwave furnace heat resources on phase transformation: A research study on red sediment placer ilmenite" Iranian Journal of Science and Technology , 2014, 38/3, 253-256

13. Satya Sai Srikant, P S Mukherjee, and R. Bhima Rao, "Morphological Characterization Of Titania Slag Obtained From Red Sediment Placer Ilmenite Using Microwave Energy" Jr of Institution of Engineers - Series D, 2015, 96/1, 43-49

\section{Figures}

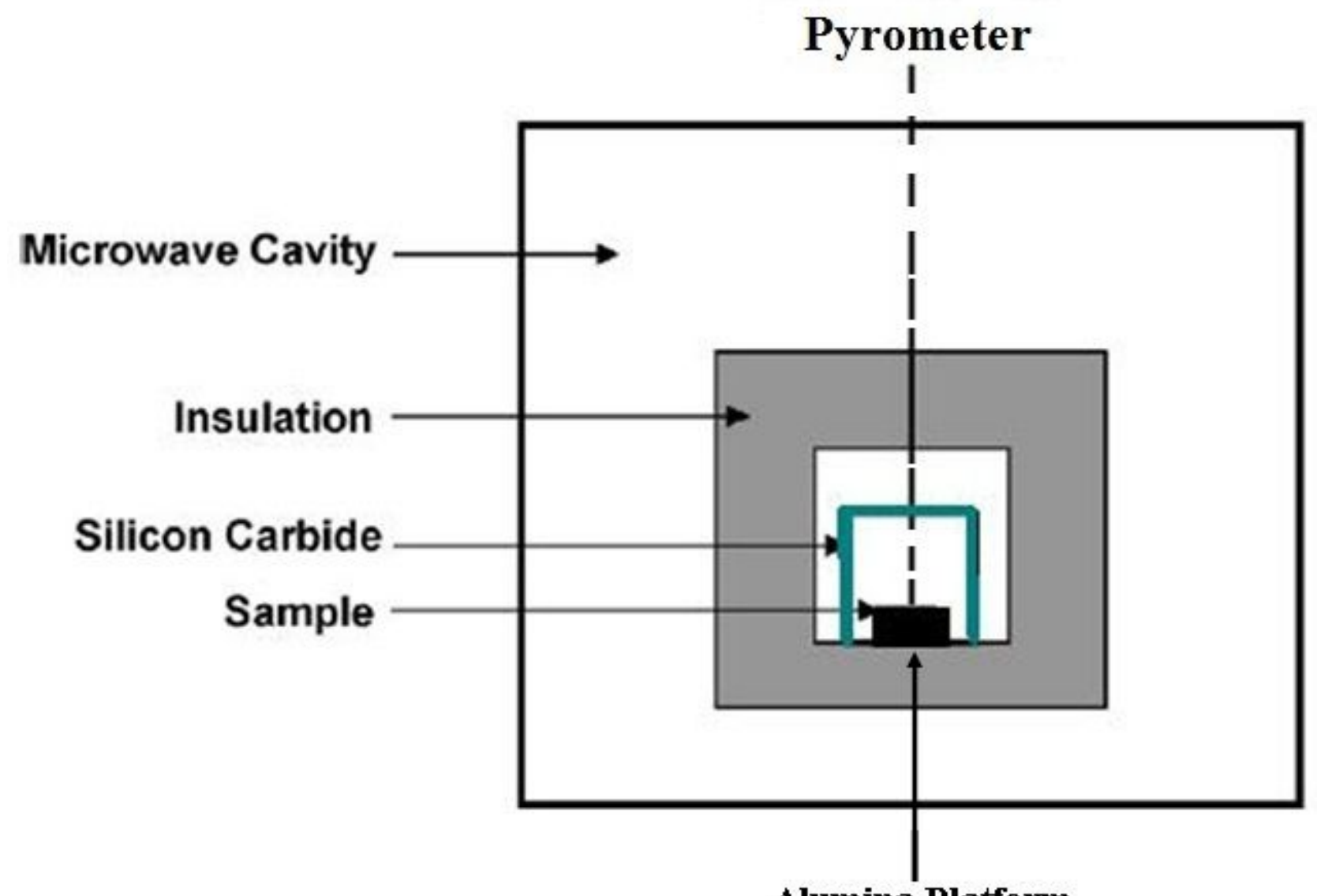

Alumina Platform 
Figure 1

Ilmenite sample heated in a microwave furnace [8]

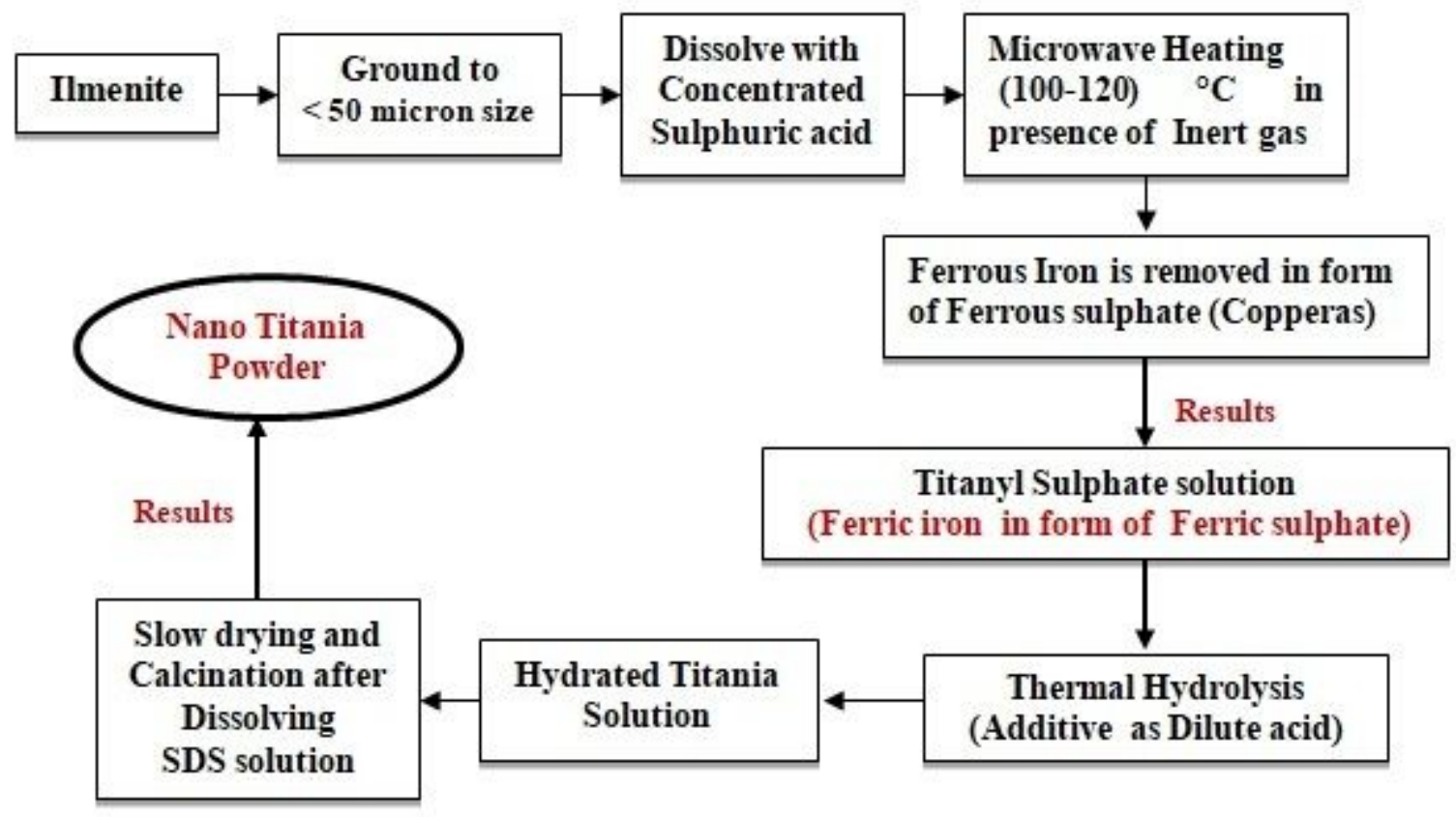

Figure 2

Flowsheet to prepare Nano-titania from Red Sediment placer ilmenite 


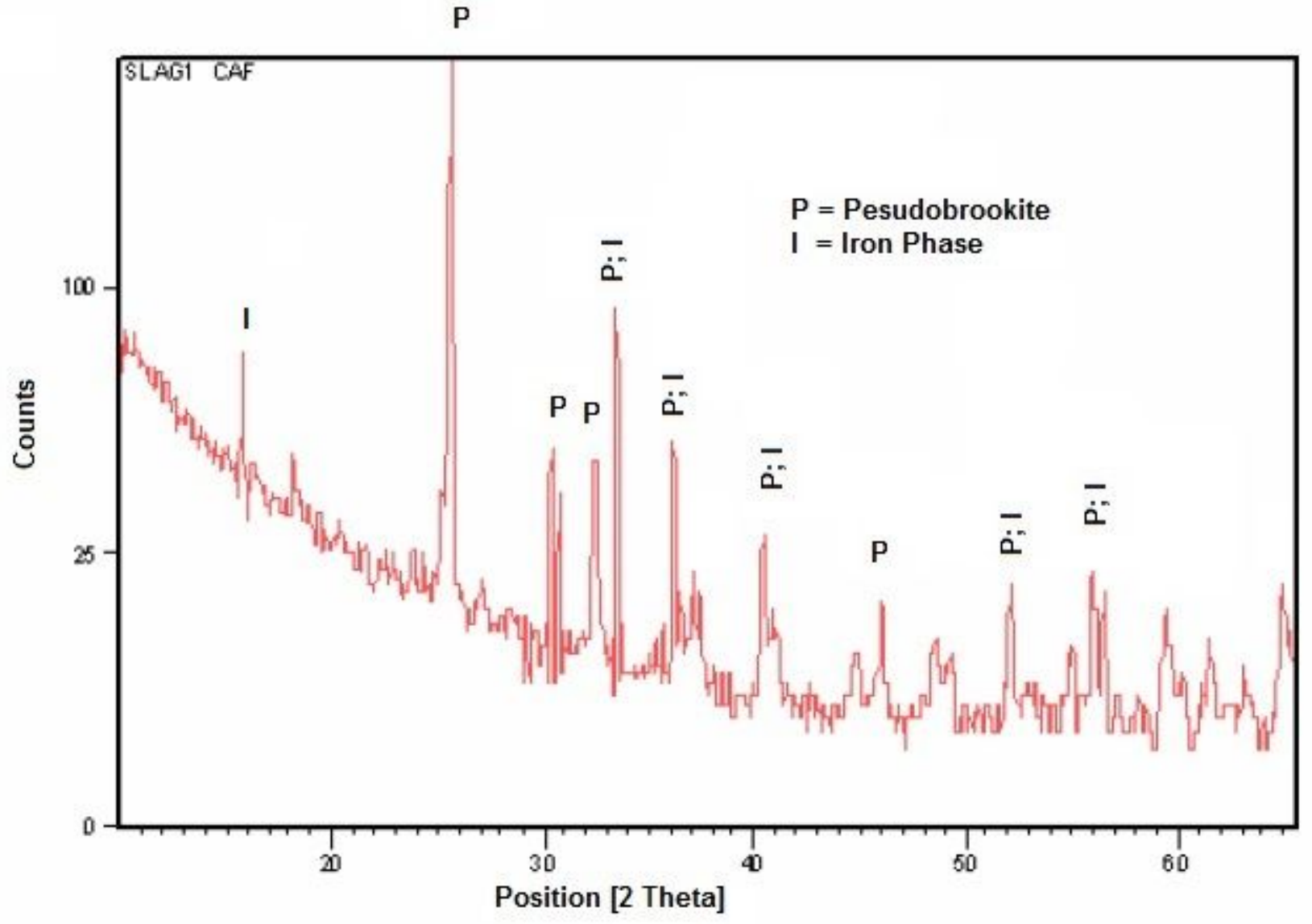

Figure 3

XRD spectrum of typical slag showing Pesudobrookite (P) and Iron phases (I)

\section{Figure 4}

XRD spectrum of Oxidized titania slag showing Pseudobrookite $(P)$, Rutile (R), Ilmenite $(X)$, and titanium dioxide $\left(\mathrm{Ti}_{3} \mathrm{O}_{5}\right)$ phases 


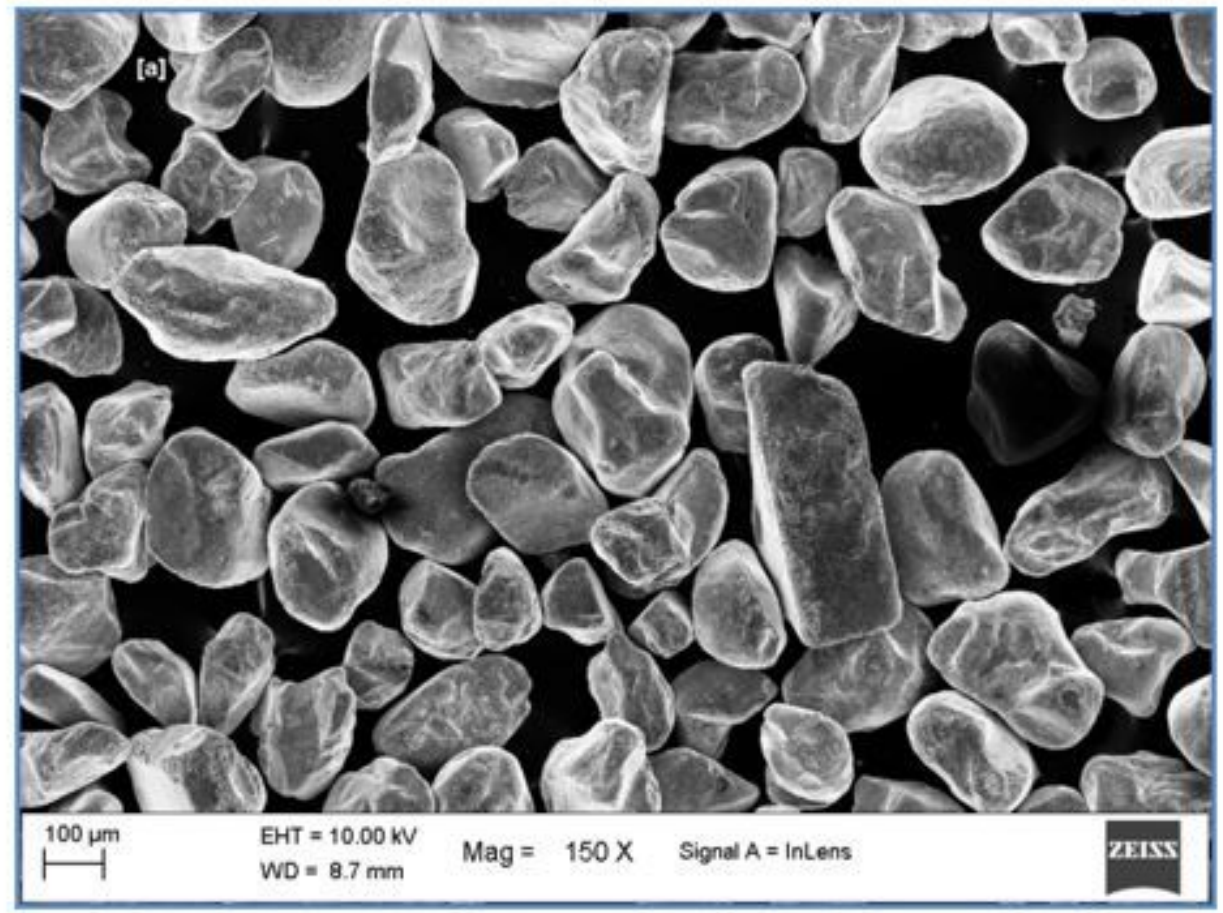

Figure 5

FESEM of ilmenite

Figure 6

FESEM of Titania rich slag

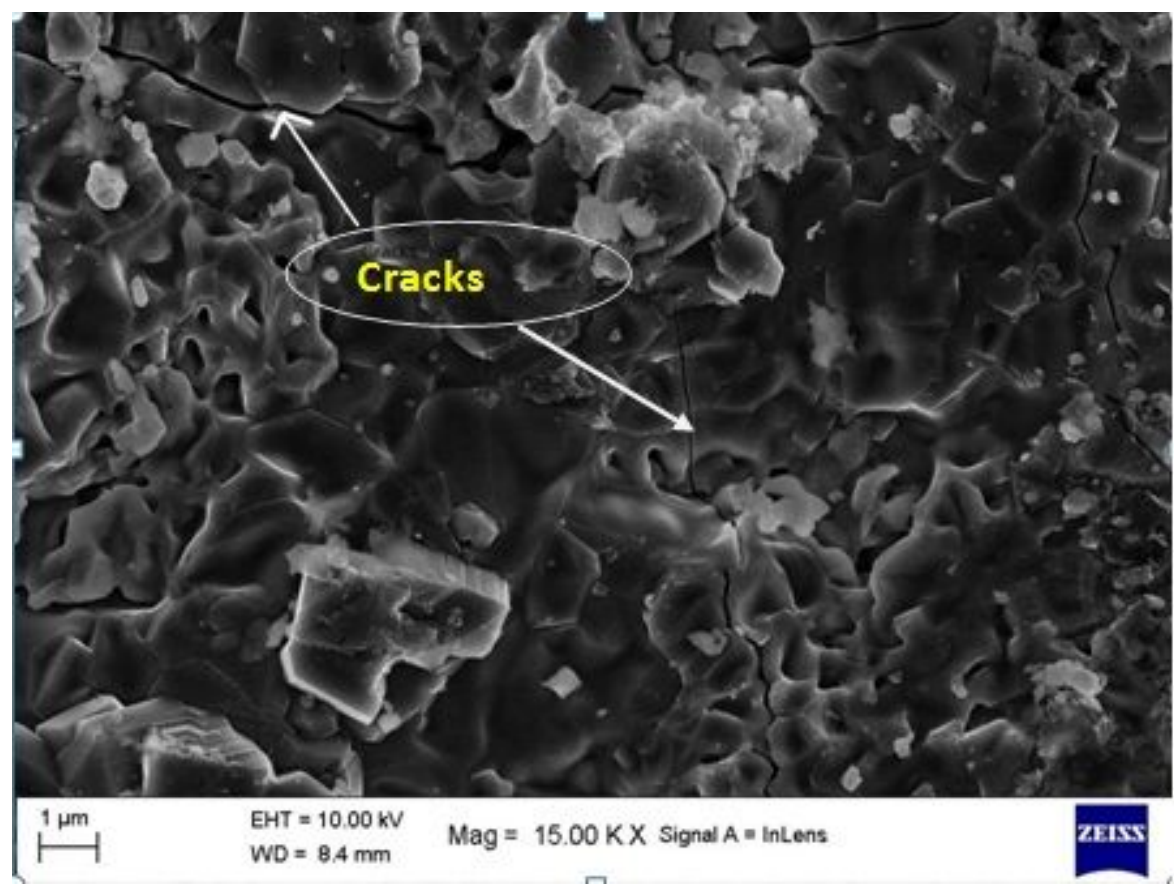


Figure 7

FESEM of Heat Treated Titania rich slag

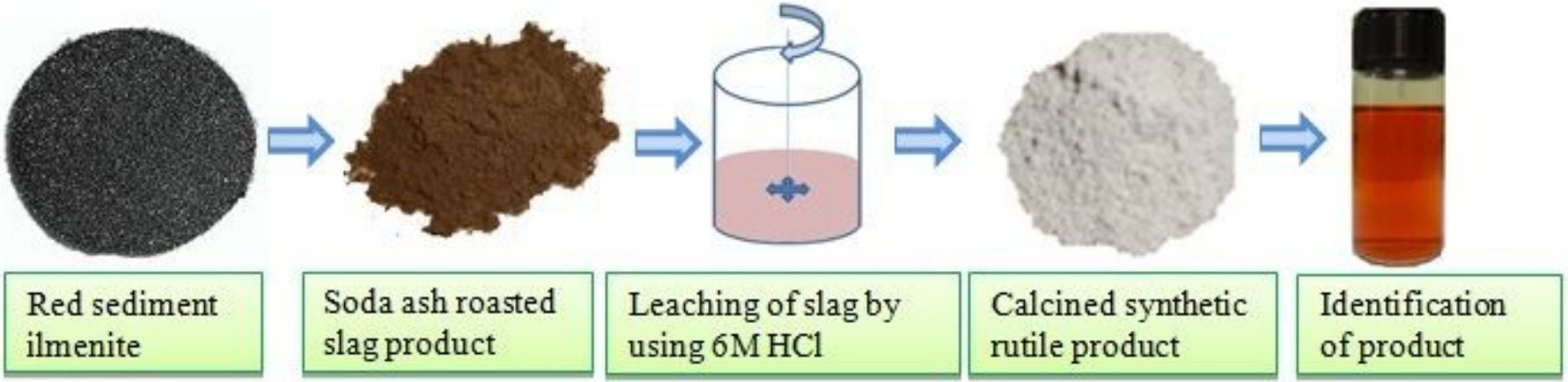

\section{Figure 8}

Leaching of red sediment ilmenite

\section{Figure 9}

XRD data of nano titanium dioxide (a) Dried @ $120^{\circ} \mathrm{C} / 1 \mathrm{~h}$ (b) Calcined @ $450^{\circ} \mathrm{C}$ (c) Dried @ $750^{\circ} \mathrm{C} / 2 \mathrm{~h}$
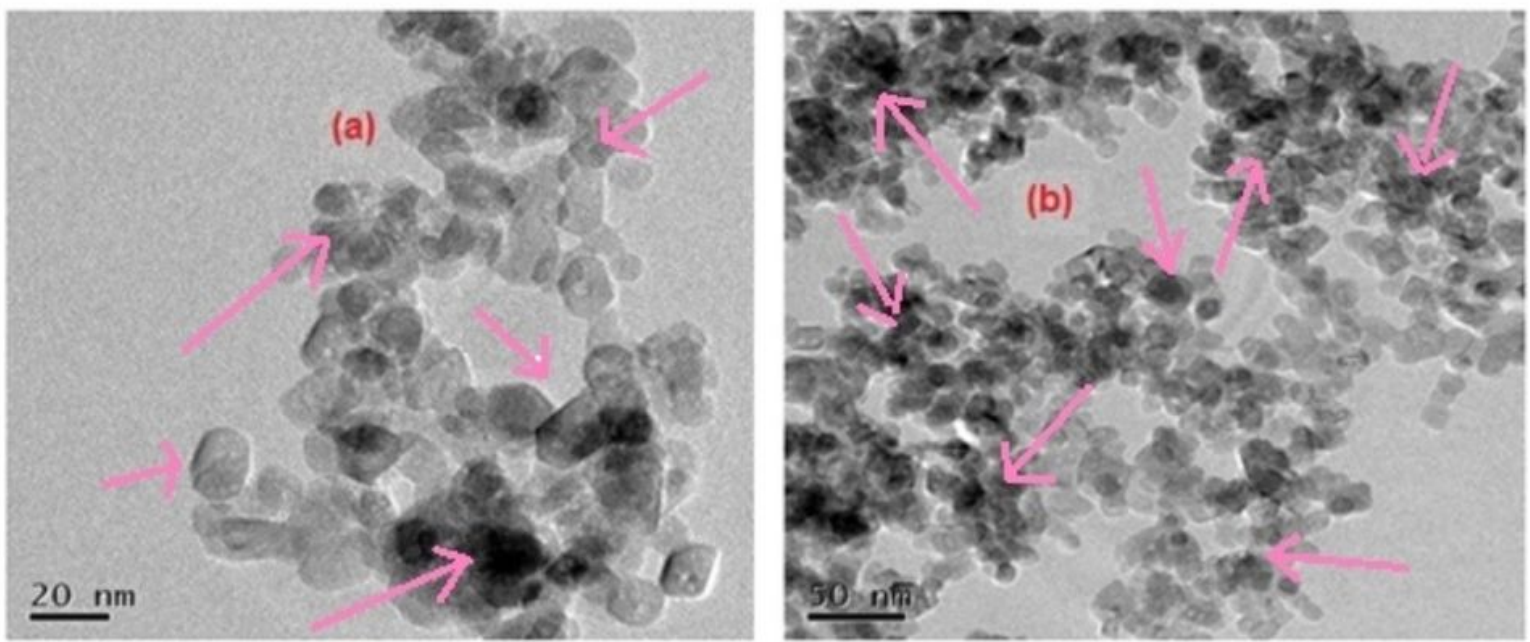

Fig 10. TEM analysis of nano- titania particles with (a) $20 \mathrm{~nm}$ resolution and (b) $50 \mathrm{~nm}$

\section{Figure 10}

TEM analysis of nano- titania particles with (a) $20 \mathrm{~nm}$ resolution and (b) $50 \mathrm{~nm}$ resolution 